\title{
Substituting Silver for Tellurium in Selenium-Tellurium Thin Films for Improving the Optical Characteristics
}

\author{
Alaa M. Abd-Elnaiem ${ }^{1}$ (D) A. M. Abdelraheem ${ }^{1}$ - M. A. Abdel-Rahim ${ }^{1} \cdot$ Samar Moustafa $^{1,2}$
}

Received: 7 January 2022 / Accepted: 7 February 2022 / Published online: 22 February 2022

(c) The Author(s) 2022

\begin{abstract}
The effect of $\mathrm{Ag}$ content on the linear and nonlinear optical characteristics of thermal evaporated $\mathrm{Se}_{90-x} \mathrm{Te}_{10} \mathrm{Ag}_{x}$ thin films, $100 \mathrm{~nm}$ thick, (where $x=0,2,4,6$, and 8 at.\%) has been examined. The optical measurements were reviewed in the wavelength range of 390-2500 nm based on the transmittance and reflectance data, and the amorphous state of the as-prepared thin film was confirmed by X-ray diffraction. The absorption coefficient, extinction coefficient, bandgap, optical density, optical conductivity, dissipation factor, and other optical properties were examined and discussed. For all of the samples, the extinction coefficient of $\mathrm{Se}_{90-\mathrm{x}} \mathrm{Te}_{10} \mathrm{Ag}_{\mathrm{x}}$ declines as the wavelength and $\mathrm{Ag}$ concentration rise, whereas the absorption coefficient increases linearly with incident photon energy. Furthermore, the optical bandgap and the width of localized states alter in the exact opposite direction, which is consistent with previously reported findings. The decrease in the optical band gap as Ag concentration increases could be attributable to an increase in the amount of disorder in the materials and the density of defect states. Other critical optoelectronic characteristics are also determined, and they are found to be influenced by the $\mathrm{Ag}$ ratio and photon wavelength. These materials may be ideal for optical memory applications due to their high absorption coefficient and compositional dependence of absorption.
\end{abstract}

Keywords Chalcogenide $\cdot \mathrm{Se}-\mathrm{Te}-\mathrm{Ag} \cdot$ Thin films $\cdot$ Optical $\cdot$ Nonlinear $\cdot$ Dispersion parameters

\section{Introduction}

Semiconductors thin films-based chalcogenide glasses are important due to their utilization in numerous scientific and technical applications. The pure $\mathrm{Se}, \mathrm{Te}$, and $\mathrm{S}$ chalcogenide has a small sensitivity, less lifetime, and high viscosity [1, 2]. The alloys and compounds containing Se are usually considered as the main component for various applications devices like optical recording, switching, memory, Xerography, etc. [2-5].

It was found that the incorporation of Se and Te exhibited considerable advantages compared to the individual $\mathrm{Se}$ or $\mathrm{Te}$ elements [6-8]. Unfortunately, the increasing temperature of the binary $\mathrm{Se}-\mathrm{Te}$ alloys over wide durations affects thermal stability. Such observed thermal instability could cause some

Alaa M. Abd-Elnaiem

abd-elnaiem@aun.edu.eg

1 Physics Department, Faculty of Science, Assiut University, Assiut 71516, Egypt

2 Physics Department, College of Science, Taibah University, Madinah, Saudi Arabia crystallization upon heating and these phenomena consider one of the drawbacks of these Se-Te alloys. Therefore, few studies have been performed to enhance the thermal stability of the Se-Te by adding third elements [9-12]. The introduction of the additional element(s) such as $\mathrm{Sn}, \mathrm{Bi}, \mathrm{Sb}, \mathrm{Ag}$, etc., to $\mathrm{Se}-\mathrm{Te}$, has special resulted in increasing the glass transition, and crystallization temperatures, hence improving the thermal stability [6-9]. The addition of Ag to $\mathrm{Se}-\mathrm{Te}$ glasses leads to an increase in the alloy density, microhardness, and generates thermal stable glass alloys [9-12].

Investigating the structural parameters of materials, e.g. chalcogenide glasses, is very useful for predicting the physical and chemical properties and could increase their performance for various applications. Different experimental methods were used to study the structural properties such as differential scanning calorimetry, X-ray diffraction, scanning, and transmission electron microscopies. Many efforts have been made in the past years to study the structural phase transition/transformation of the chalcogenide glasses. In our previous work, the effect of $\mathrm{Ag}$ additive in $\mathrm{Se}-\mathrm{Te}$ on the crystallization process was studied $[10,13]$. Singh 
and others studied the influence of $\left(\mathrm{Se}_{80} \mathrm{Te}_{20}\right)_{96} \mathrm{Ag}_{4}$ thin film thickness on their optical parameters $[14,15]$.

Recently, our group reported on the pre-crystallization and crystallization characteristics for $\mathrm{Se}_{90-x} \mathrm{Te}_{10} \mathrm{Ag}_{x}$ glasses $[10,13]$. The linear and nonlinear optical characteristics of $\mathrm{Se}_{90-x} \mathrm{Te}_{10} \mathrm{Ag}_{x}$ films have been described in further depth in this work. The purpose of Ag addition is to improve the electronic characterization of Se-Te amongst other properties such as the thermal stability. The addition of Ag in binary $\mathrm{Se}-\mathrm{Te}$ alloy is predictable to enhance the optical parameters of the $\mathrm{Se}_{90} \mathrm{Te}_{10}$ alloy by the replacement of $\mathrm{Se}$ atoms.

\section{Experimental Details}

The fabrication of the $\mathrm{Se}_{90-x} \mathrm{Te}_{10} \mathrm{Ag}_{x}(x=0,2,4,6$, and 8 at.\%) bulk alloys available in detail elsewhere [10]. The powder of these bulk was evaporated in a high vacuum chamber $\left(10^{-5} \mathrm{mbar}\right)$ using the thermal evaporation technique. The films were thermally evaporated on cleaned glass substrates. The glass substrates were rotated horizontally above the hot tungsten boat that was used to evaporate the powders of the alloys inside the chamber. The purpose of the rotation of the substrate was to increase the homogeneity of the thickness of the evaporated films. The thickness of the films was adjusted by evaporating specific weights of alloy powders using a weight-thickness curve that was pre-calibrated. The produced thin film thickness was measured with a quartz crystal thickness monitor (FTM5, Edwards) and determined to be $100 \mathrm{~nm}$.

$\mathrm{X}$-ray diffraction (XRD) was used to establish the amorphous nature of the thermally evaporated $\mathrm{Se}_{90-x} \mathrm{Te}_{10} \mathrm{Ag}_{x}$ thin films using a Philips 1710 diffractometer. The XRD diffractometer supplies $\mathrm{CuK}_{\alpha}$ radiation of $\lambda$ equals $1.5418 \AA$ and was working at $40 \mathrm{kV}$ and $30 \mathrm{~mA}$. The XRD patterns were recorded from $2 \theta$ equals 4 to $70^{\circ}$ with a scanning rate of $3.6 \%$ min.

The optical reflectance $R(\lambda)$, and transmittance $T(\lambda)$ of the $\mathrm{Se}_{90-x} \mathrm{Te}_{10} \mathrm{Ag}_{x}$ films were determined, for $\lambda$ range of $390-2500 \mathrm{~nm}$, using a double beam spectrophotometer (Perkin-Elmer Lambda 750). More details related to the optical measurement setup are available elsewhere [16, 17].

\section{Results and Discussion}

Energy-dispersive X-ray analysis (EDX) was used to determine the elemental compositions of evaporated $\mathrm{Se}_{90-x} \mathrm{Te}_{10} \mathrm{Ag}_{x}$ thin films. Figure $1 \mathrm{a}$ and $\mathrm{b}$ show selected EDX charts for $\mathrm{Se}_{90} \mathrm{Te}_{10}$ and $\mathrm{Se}_{82} \mathrm{Te}_{10} \mathrm{Ag}_{8}$ thin films placed on a glass substrate. The peak caused by silicon that presence soda-lime glass under the produced layers was removed,

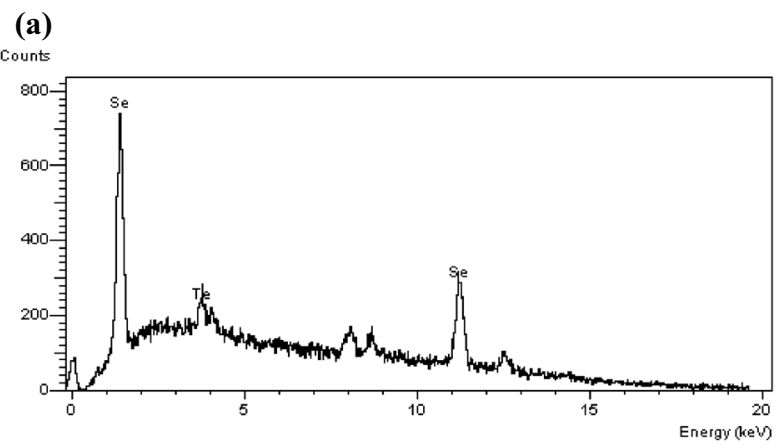

(b)
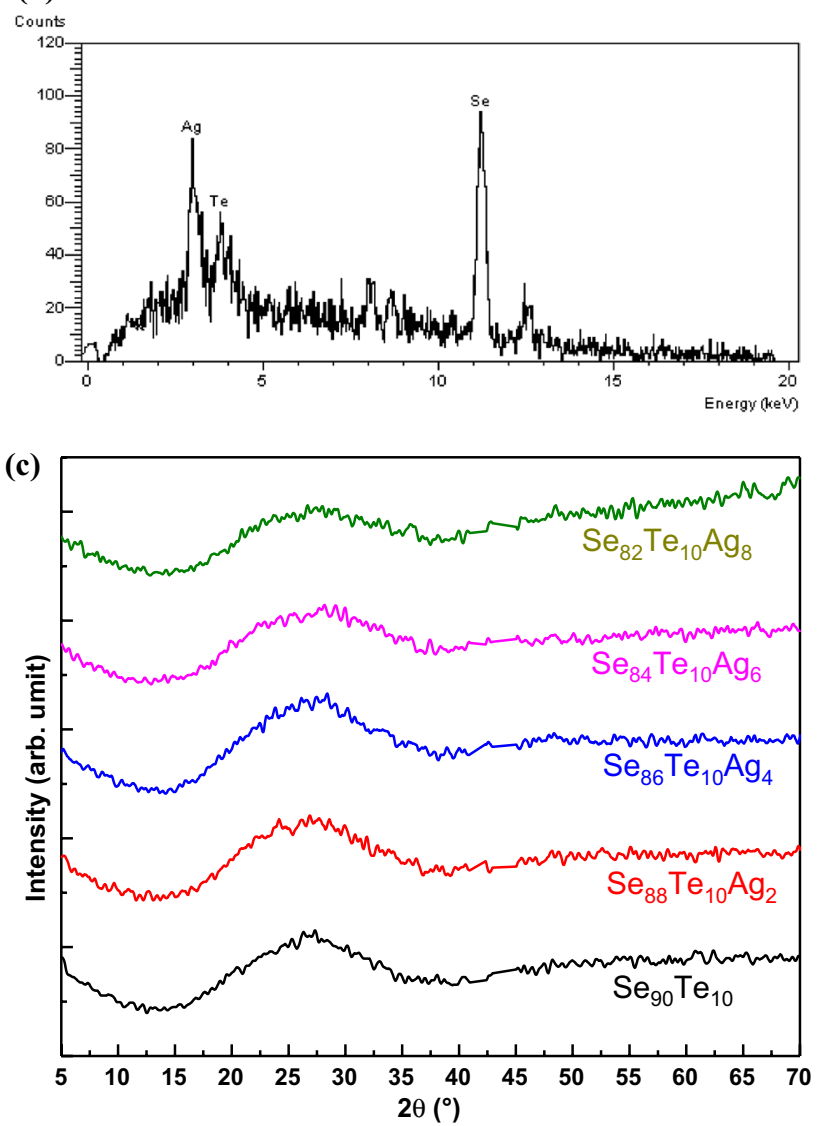

Fig. 1 Energy dispersive X-ray analysis (EDX) for a $\mathrm{Se}_{90} \mathrm{Te}_{10}$, and $\mathbf{b} \mathrm{Se}_{82} \mathrm{Te}_{10} \mathrm{Ag}_{8}$ thin films. c XRD charts for the as-prepared $\mathrm{Se}_{90-x} \mathrm{Te}_{10} \mathrm{Ag}_{x}$ films (where $x=0,2,4,6$, and 8 at.\%)

and the ratio for the other elements, e.g. Se, Te, and $\mathrm{Ag}$, was estimated. According to the data shown in Fig. 1a, the atomic percentage ratio of $\mathrm{Se}$ and $\mathrm{Te}$ is $86.25 \%$ and $13.75 \%$, respectively, matching with the proposed $\mathrm{Se}_{90} \mathrm{Te}_{10}$ films. On the other hand, the elemental compositions of $\mathrm{Se}, \mathrm{Ag}$, and Te are 78.82 at.\%, 10.01 at.\%, and 11.17 at.\%, respectively, corresponding to the proposed $\mathrm{Se}_{82} \mathrm{Te}_{10} \mathrm{Ag}_{8}$ films, as shown in Fig. 1b. The evaluated value of the element concentration for all thin films was closed to the proposed concentration. 
The glassy nature of the as-prepared bulk samples of $\mathrm{Se}_{90-x} \mathrm{Te}_{10} \mathrm{Ag}_{x}$ was confirmed through the DSC analysis in our published work [10]. Besides, the XRD was performed to check the crystal nature of the thermal evaporated $\mathrm{Se}_{90-x} \mathrm{Te}_{10} \mathrm{Ag}_{x}$ thin films as illustrated in Fig. 1c. It is shown that no sharp peaks can be distinguished in the diffractograms confirming the noncrystalline (amorphous) nature of the formed $\mathrm{Se}_{90-x} \mathrm{Te}_{10} \mathrm{Ag}_{x}$ thin films. The absence of any diffraction peaks related to $\mathrm{Ag}$ or $\mathrm{Ag}$-based phases could confirm the good distribution of $\mathrm{Ag}$ atoms inside the amorphous matrix.

Figure $2 a$ and $b$ show $T(\lambda)$, and $R(\lambda)$, respectively, versus photon wavelength $(\lambda)$ for the as-prepared $\mathrm{Se}_{90-x} \mathrm{Te}_{10} \mathrm{Ag}_{x}$ thin films. The trend of $T(\lambda)$ curves, as shown in Fig. 2a, can be divided into two different stages are recorded at a wavelength $(\lambda)$ range equal $390-950$ and $950-2500 \mathrm{~nm}$. Initially, $T(\lambda)$ is sharply increased with increasing $\lambda$ and has a maximum value $(\sim 0.75)$ at $\lambda$ equals $950 \mathrm{~nm}$, and then a slowly dropped to the plateau region, 0.6 , for a higher $\lambda$. On the other hand, the value of $T(\lambda)$ increases as Ag content increases, while $R(\lambda)$ has an opposite behavior. Meanwhile,
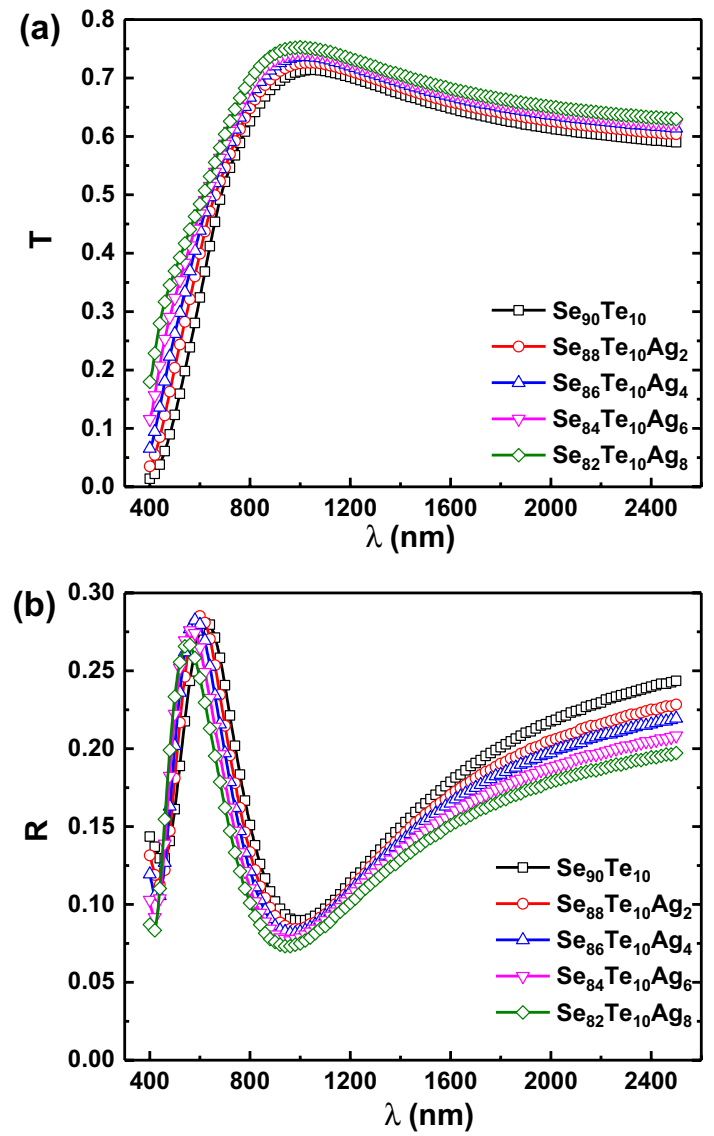

Fig. 2 The optical a transmittance $(\mathrm{T})$ and $\mathbf{b}$ reflectance $(\mathrm{R})$ for the as-prepared $\mathrm{Se}_{90-x} \mathrm{Te}_{10} \mathrm{Ag}_{x}$ films as functions of photon wavelength $(\lambda)$
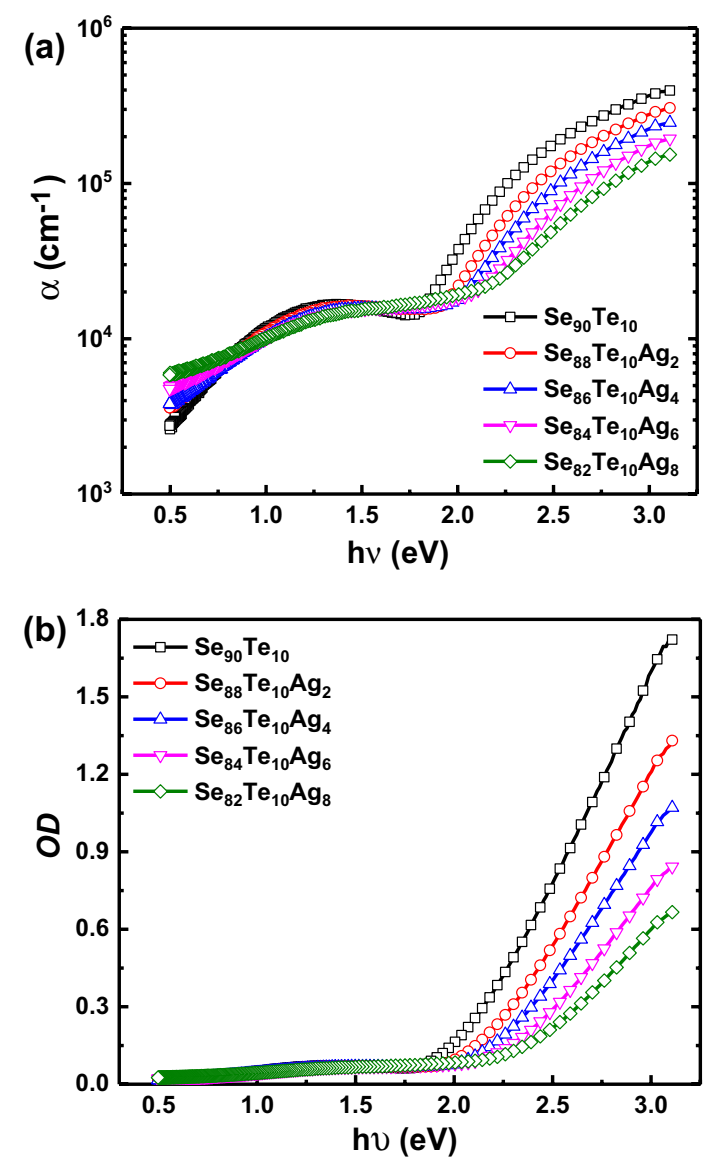

Fig. 3 a The absorption coefficient $(\alpha)$ and $\mathbf{b}$ the optical density $(O D)$ as functions of photon energy $(\mathrm{h} \nu)$ of the as-prepared $\mathrm{Se}_{90-x} \mathrm{Te}_{10} \mathrm{Ag}_{x}$ films

a maximum value of $T(\lambda)$ is observed, the $R(\lambda)$ has minimum values in the range $850-950 \mathrm{~nm}$ as illustrated in Fig. 2b. Generally, for a higher wavelength $(\lambda>1000 \mathrm{~nm})$, the $T(\lambda)$ increases with increasing $\mathrm{Ag}$ content, while $\mathrm{R}(\lambda)$ has an opposite trend.

The absorption coefficient $(\alpha)$ for the studied films with a thickness $d$ can be calculated from $\mathrm{R}(\lambda)$ and $\mathrm{T}(\lambda)$ data, using the next formula [18]:

$T(\lambda)=\frac{(1-R)^{2} e^{-\alpha d}}{1-R^{2} e^{-2 \alpha d}}$

Figure 3a shows the estimated values of $\alpha$ for the as-prepared $\mathrm{Se}_{90-x} \mathrm{Te}_{10} \mathrm{Ag}_{x}$ thin films. It was seen that the value of $\alpha$ was enhanced as $h \nu$ was increased, but it reduces with the increase in $\mathrm{Ag}$ ratio for $\mathrm{h} \nu>2 \mathrm{eV}$. There is a stable plateau region of $\alpha$, at $1.6 \times 10^{4} \mathrm{~cm}^{-1}$, is observed in the range of energy equal to $1.1-1.8 \mathrm{eV}$. In another hand, for lower energy $(\mathrm{h} \nu<0.9 \mathrm{eV})$ the change in $\alpha$ with the content of $\mathrm{Ag}$ shows an opposite trend as it was raised for greater Ag content. 
Fig. 4 The plots of $\mathbf{a}(\alpha h \nu)^{2}, \mathbf{b}(\alpha h \nu)^{1 / 2}$, and $\mathbf{c} \ln (\alpha)$ versus photon energy $(\mathrm{h} \nu)$, and $\mathbf{d}$ the indirect energy gap $\left(E_{g}^{\text {ind }}\right)$, and the width of the localized states $\left(E_{e}\right)$ as a function of $\mathrm{Ag}$ content for the as-prepared $\mathrm{Se}_{90-x} \mathrm{Te}_{10} \mathrm{Ag}_{x}$ films

Optical density $(O D)$ describes the refraction of electromagnetic light inside a matter, therefore, giving useful information about the transmission of light inside the materials. The value of $O D$ as a function of $\alpha$ and $d$ for material is given by:

$O D=0.434 \alpha d$

Figure $3 \mathrm{~b}$ shows the plots of $O D$ against $\mathrm{h} \nu$ for $\mathrm{Se}_{90-x} \mathrm{Te}_{10} \mathrm{Ag}_{x}$ thin films calculated from Eq. 2. The plotted curves are composed of two distinct sections; at lower $h \nu$, the change of $O D$ can be neglected and has a small value less than 0.07. However, the second section in $O D$ curves $(\mathrm{h} \nu>1.75 \mathrm{eV})$ reveals a significant increase in the $O D$ with increasing h $\nu$. On the other hand, the value of the $O D$ was reduced to lower values for a higher content of $\mathrm{Ag}$. The observed decrease in the $O D$ could be attributed to the absorbance of the light that happened inside the material.

According to the Tauc extrapolation method, the relation between $\alpha$ and $h \nu$ in the high absorption region is governed by the following expression [19]:

$\alpha h v=B\left(h v-E_{g}\right)^{s}$

where $B$ is a constant that is influenced by the probability of transition, and $s$ is a number that determines the transition type and equals $1 / 2$, and 2 for directly, and indirectly allowed transitions, respectively. For simplicity, we have plotted the relations between $(\alpha h v)^{2}$, and $(\alpha h v)^{1 / 2}$ versus $(h v)$ for the studied $\mathrm{Se}_{90-x} \mathrm{Te}_{10} \mathrm{Ag}_{x}$ films as shown in Figs. $4 \mathrm{a}$, and $4 \mathrm{~b}$, respectively. The plot illustrates good linearity over a broad range of $h v$ as shown in Fig. $4 \mathrm{~b}$ which indicates the dominant optical transition is allowed indirect type transition for the studied compositions. The extrapolating of the linear part to zero absorption in the $(\alpha h v)^{1 / 2}-h v$ curves that shown in Fig. $4 \mathrm{~b}$ gives the value of $E_{g}^{\text {ind }}$. The values of $E_{g}^{\text {ind }}$ as a function of $\mathrm{Ag}$ content presented in Fig. $4 \mathrm{~d}$. The value of $E_{g}^{\text {ind }}$ increases from 1.65 to $1.89 \mathrm{eV}$ as the $\mathrm{Ag}$ contents increase from 0 at.\% to 8 at.\% as illustrated in Table 1. This observation means the value of $E_{g}^{\text {ind }}$ or the optoelectronic properties of the studied films could be controlled by the substitution of Se by $\mathrm{Ag}$ in the $\mathrm{Se}_{90-x} \mathrm{Te}_{10} \mathrm{Ag}_{x}$ alloys. Similar observations, the increases in the optical band gap, were achieved by the substitution of $\mathrm{Te}$ or $\mathrm{Se}-\mathrm{Te}$ by $\mathrm{Ag}$ atoms in the ternary Se-Te-Ag $[9,14]$.

For $\alpha$ that lies in the range between $10^{0}$ and $10^{4} \mathrm{~cm}^{-1}$, the so-called Urbach edge in which the relation between $\alpha$ and $h v$ obeys an exponential trend according to Urbach relation [20]:
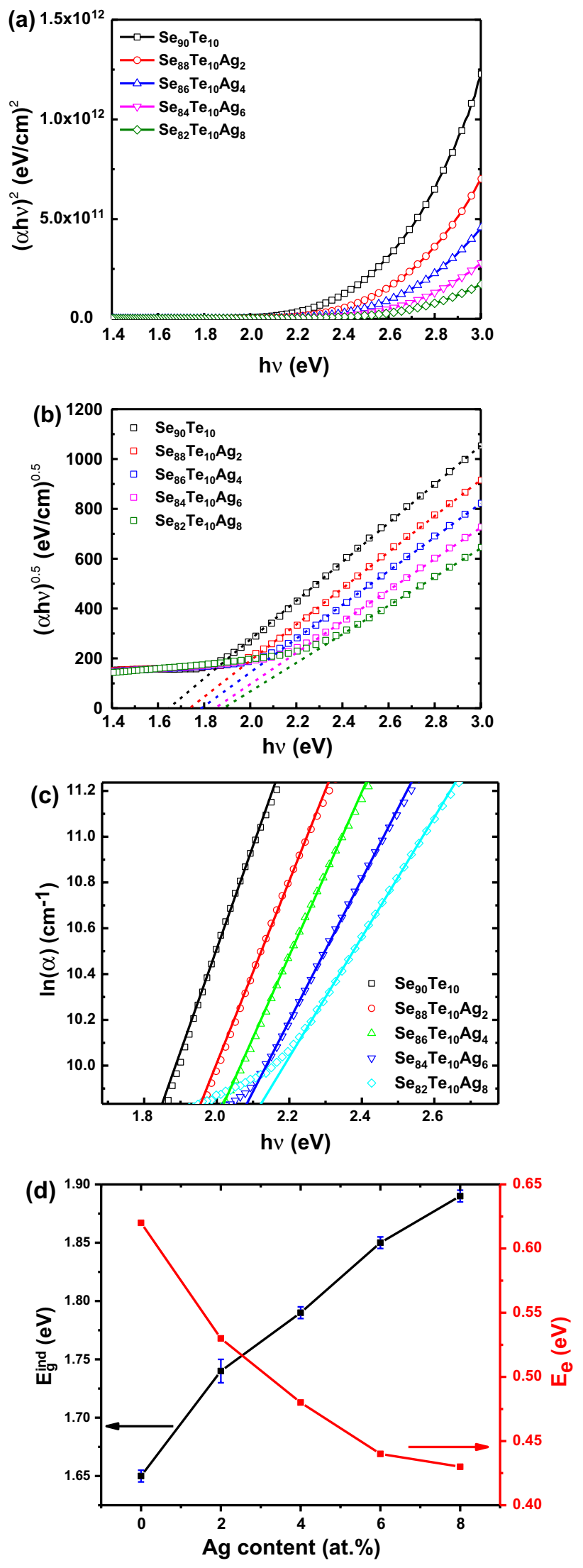
Table 1 The optical energy gap $\left(E_{g}\right)$, the width of localized state energy $\left(E_{e}\right)$, dispersion energy $\left(E_{d}\right)$, oscillator energy $\left(E_{o}\right)$, highfrequency dielectric constant $\left(\varepsilon_{\infty}\right)$, the ratio between the free carrier concentration $(N)$ to the effective electron mass $\left(m^{*}\right)$ for as-prepared $\mathrm{Se}_{90-x} \mathrm{Te}_{10} \mathrm{Ag}_{x}$ thin film

\begin{tabular}{lrrrrr}
\hline Parameter & $x=0$ & $x=2$ & $x=4$ & $x=6$ & $x=8$ \\
\hline$E_{g}^{\text {ind }}(\mathrm{eV})$ & 1.65 & 1.74 & 1.79 & 1.85 & 1.89 \\
$E_{e}(\mathrm{eV})$ & 0.62 & 0.53 & 0.48 & 0.44 & 0.43 \\
$\mathrm{E}_{\mathrm{o}}(\mathrm{eV})$ & 3.61 & 2.62 & 2.50 & 2.45 & 2.45 \\
$\mathrm{E}_{\mathrm{d}}(\mathrm{eV})$ & 22.74 & 9.89 & 7.57 & 6.26 & 5.53 \\
$\varepsilon_{o}$ & 7.30 & 4.77 & 4.03 & 3.56 & 3.26 \\
$\lambda_{o}(\mathrm{~nm})$ & 605.88 & 605.19 & 601.36 & 595.97 & 590.52 \\
$\mathrm{~S}_{\mathrm{o}} \times 10^{-6}\left(\mathrm{~nm}^{-2}\right)$ & 4.58 & 4.04 & 3.81 & 3.63 & 3.48 \\
$\varepsilon_{L}$ & 18.7 & 20.46 & 19.58 & 17.7 & 15.7 \\
$N / m^{*} \times 10^{58}\left(\mathrm{~m}^{-3} \mathrm{~kg}^{-1}\right)$ & 2.08 & 1.70 & 1.43 & 1.26 & 1.08 \\
$n_{\mathbf{o}}$ & 2.70 & 2.19 & 2.01 & 1.89 & 1.80 \\
\hline
\end{tabular}

$\alpha(v)=\alpha_{o} e^{\left(\frac{h v}{E_{e}}\right)}$

where $v$ is the frequency of the electromagnetic wave, $\alpha_{o}$ is constant that equals the absorption at zero frequency, and $E_{e}$ is the Urbach energy. Figure $4 \mathrm{c}$ shows a linear dependence between $\ln (\alpha)$ and $h v$ for the investigated $\mathrm{Se}_{90-x} \mathrm{Te}_{10} \mathrm{Ag}_{x}$ films. The inverse of the slope of the fitted lines was used to get the value of $E_{e}$ for each composition. The evaluated $E_{e}$ and $E_{g}^{\text {ind }}$ as a function of the film's composition for $\mathrm{Se}_{90-x} \mathrm{Te}_{10} \mathrm{Ag}_{x}$ films is shown in Fig. 4d. Besides, the influence of $E_{e}$ and $E_{g}^{i n d}$ on the Ag concentration for $\mathrm{Se}_{90-x} \mathrm{Te}_{10} \mathrm{Ag}_{x}$ thin films is summarized in Table 1. It is shown from this figure that $E_{e}$ decreased from 0.62 to $0.43 \mathrm{eV}$, with raising $\mathrm{Ag}$ ratio from 2 to 8 at.\% which exactly opposite to change of $E_{g}^{\text {ind }}$.

The behavior of the optical bandgap versus Ag content can be explained according to the Kastner et al. model [21, $22]$. In the chalcogenide glasses, the valence band is constituted of lone pair p-orbitals that were supplied by the chalcogen atoms, according to this concept. The energies of lone pair electrons close to electropositive atoms will be higher than those of electronegative atoms. As a result, adding electropositive elements to the matrix may increase the energy of the lone pair states, causing the valence band to expand inside the prohibited gap. Se, Te, and Ag have electronegativities of 2.4, 2.1, and 1.93, respectively. Because Ag has lower electronegative compared to Se, replacing Ag with Se could increase the energy of some lone pair states, thereby expanding the valence band. As a result, the band tailing $\left(E_{e}\right)$ diminishes as the Ag content rises. In addition, structural flaws such as unfulfilled bonding may lower the value of $E_{e}$.

The increase of $E_{g}^{\text {ind }}$ with $\mathrm{Ag}$ content for $\mathrm{Se}_{90-x} \mathrm{Te}_{10} \mathrm{Ag}_{x}$ thin films can be understood by using the structural analysis of the Se-Te system. For the alloy rich with Se, the atomic
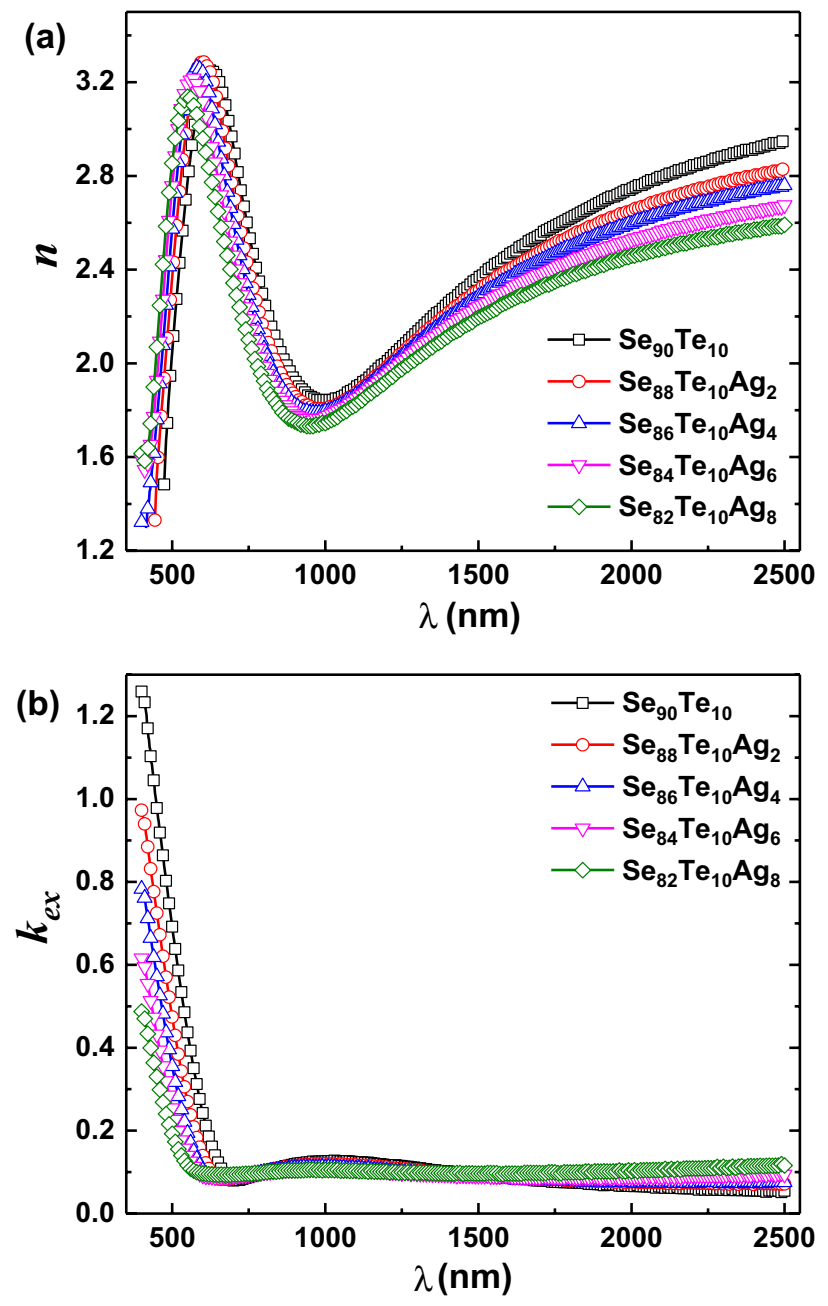

Fig. 5 The variation of $\mathbf{a}$ refractive index $(n)$ and $\mathbf{b}$ extinction coefficient $\left(k_{e x}\right)$ with wavelength $(\lambda)$ for the as-prepared $\mathrm{Se}_{90-x} \mathrm{Te}_{10} \mathrm{Ag}_{x}$ films

structure is composed of Se chains that are linked with $\mathrm{Te}$ atoms [23]. Moreover, the addition of Ag elements creates dangling bonds which increase the density of localized states near the band edges. Accordingly, the increase in density of state gives an increase in the optical energy bandgap $E_{g}^{\text {ind }}$.

Evaluating the complex optical constants, for example, the complex refractive index $\left(\tilde{n}=n+i k_{e x}\right)$, utilizes for understanding the optical characteristics of transparent solid substances. The real and imaginary parts of $\tilde{n}$ can be calculated at a specific value of $\lambda$ using the following relationships [24, 25]:

$n=\frac{1+R}{1-R}+\sqrt{\left(\frac{1+R}{1-R}\right)^{2}-\left(\frac{\alpha \lambda}{4 \pi}\right)^{2}-1}$

$k_{e x .}=\frac{\alpha \lambda}{4 \pi}$ 
Figure 5a and $\mathrm{b}$ show the plots of $n$ and $k_{e x}$ against $\lambda$ for the thermally evaporated $\mathrm{Se}_{90-x} \mathrm{Te}_{10} \mathrm{Ag}_{x}$ thin films, respectively. Generally, the $n-\lambda$ curves for $\mathrm{Se}_{90-x} \mathrm{Te}_{10} \mathrm{Ag}_{x}$ thin films are very similar to the $\mathrm{R}-\lambda$ curves. The refractive index is influenced by the $\mathrm{Ag}$ or Se content and $\lambda$. Its maximum value $\left(n_{\max }\right)$ was observed at a critical wavelength $\left(\lambda_{\mathrm{c}}\right)$ which is shifted towards lower $\lambda$ for a greater ratio of Ag. Also, at a higher wavelength $(\lambda>600 \mathrm{~nm})$ the refractive index $(n)$ decreased with increasing $\lambda$, and then enhanced again for $\lambda>1000 \mathrm{~nm}$. The value of $n_{\max }(3.1-3.3)$ was observed at $\lambda_{\mathrm{c}}=600 \pm 10 \mathrm{~nm}$, while $n_{\min }(1.7-1.8)$ was observed at $\lambda_{\mathrm{c}}=950 \pm 10 \mathrm{~nm}$. On the other hand, the value of $k_{e x}$ is significantly decreased from 1.2 to 0.1 with increasing $\lambda$ from 400 to $600 \mathrm{~nm}$ and becomes constant for further increasing $\lambda$. Similarly, its value was decreased as the $\mathrm{Ag}$ concentration was increased as illustrated in Fig. 5b. However, at a higher wavelength $(\lambda>1000 \mathrm{~nm})$, the value of $n$ was decreased with increasing the $\mathrm{Ag}$ ratio or decreasing the Se ratio. The decrease in the $n$ and $k_{e x}$ value with increasing $\lambda$ can be interpreted as the result of an increase in $T(\lambda)$ and a decrease in $\alpha$ with increasing $\lambda$. On the other hand, the reduction in $n$ in the smaller range of $\lambda(490 \leq \lambda(\mathrm{nm}) \leq 1000)$ shows the normal dispersion trend of substances. Furthermore, the change in $n$ and $k_{e x}$ by Ag doping can be ascribed to the change in the glass density that is caused by structural rearrangement, and the change in the mean of polarizability causes the formation of heteropolar bonds. As shown the density of states and mean polarizability are the two factors that contribute to the variation in refractive index and extinction coefficient. This inverse behavior could be attributed to the decrease in $\alpha$ with the increase in $\lambda$.

The dispersion of $n$ is evaluated using the theory of the single oscillator model reported by the Wemple-DiDomenico (WDD) as follows [26]:

$\left(n^{2}-1\right)^{-1}=-\frac{(h \nu)^{2}}{E_{d} E_{0}}+\frac{E_{0}}{E_{d}}$

where $E_{d}$ is the dispersion energy, and $E_{0}$ is the effective oscillation energy. The numerical values of $E_{0}$ and $E_{d}$ can be calculated from the linear fit of the plot of $\left(n^{2}-1\right)^{-1}$ versus $(\mathrm{h} \nu)^{2}$ as shown in Fig. 6a. The determined values of $E_{0}$ and $E_{d}$ for different compositions of $\mathrm{Se}_{90-x} \mathrm{Te}_{10} \mathrm{Ag}_{x}$ films are shown in Table 1 . It has appeared that $E_{0}, E_{d}$ and $n_{0}$ are decreased with rising Ag concentration. Furthermore, the values of static refractive index $\left(n_{0}=\sqrt{1+\frac{E_{d}}{E_{0}}}\right)$ are attained by rewriting Eq. 7 at $h v \rightarrow 0$, and the obtained values of the three parameters $E_{d}, E_{0}$ and $n_{0}$ are listed in Table 1. The reduction of $E_{0}$ when $\mathrm{Ag}$ content was increased could be interpreted to the shift of transmission spectra nearing the larger wavelength.

To gain an obvious view of the optical characteristics of the chalcogenide thin films under investigation, various
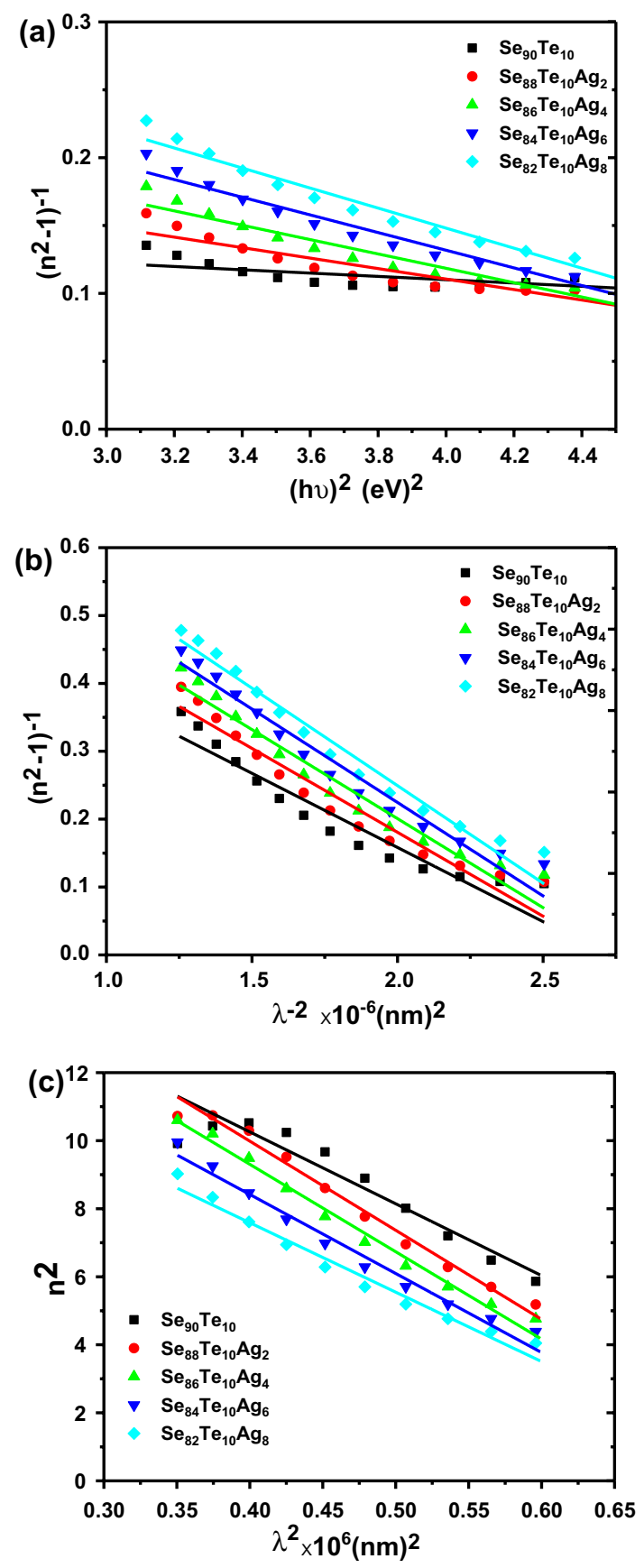

Fig. 6 Plot of $\mathbf{a}\left(\mathrm{n}^{2}-1\right)^{-1}$ versus $(h \nu)^{2}, \mathbf{b}\left(\mathrm{n}^{2}-1\right)^{-1}$ versus $\lambda^{-2}$ and $\mathbf{c}$ $n^{2}$ versus $\lambda^{2}$ for the as-prepared $\mathrm{Se}_{90-x} \mathrm{Te}_{10} \mathrm{Ag}_{x}$ films

optical constants like the high-frequency dielectric constant $\left(\varepsilon_{L}\right)$ and carrier concentration should be determined $(N)$. There are two procedures to determine $\varepsilon_{L}$ using the data of $n$ at various $h v$.

The first procedure is based on the dispersion that occurs when bond carriers in an empty lattice are interacting. This approach, $\left(\varepsilon_{\mathrm{o}}=n_{0}^{2}\right)$ can be derived from the single term 
Sellmeir oscillation model and the following basic classical dispersion relation can be used [27]:

$\frac{n_{0}^{2}-1}{n^{2}-1}=1-\frac{\lambda_{0}^{2}}{\lambda^{2}}$

where $\lambda_{\mathrm{o}}$ is the average inter-band oscillator wavelength. Equation 8 can be rewritten as:

$\left(n^{2}-1\right)^{-1}=\frac{1}{S_{0} \lambda_{0}}-\frac{1}{S_{0} \lambda^{2}}$

Figure $6 \mathrm{~b}$ presents the plot between $\left(n^{2}-1\right)^{-1}$ and $\lambda^{-2}$ which $x$ gives straight lines. The numerical values of $S_{0}$ for the studied $\mathrm{Se}_{90-x} \mathrm{Te}_{10} \mathrm{Ag}_{x}$ samples can be calculated using $S_{o}=\frac{n_{0}^{2}-1}{\lambda_{o}^{2}}$. The deduced values of $\lambda_{o}, n_{o}$ and $S_{o}$ are summarized in Table 1 . The calculated values of $\lambda_{o}, n_{o}$, and $S_{o}$ decreased with increasing Ag content.

The contribution of free carriers and dispersion lattice vibration modes is included in the second approach which is used for estimating $\varepsilon_{L}$. In this case, the value of $\varepsilon_{L}$ and the ratio of the free electron concentration $N$ to the electron effective mass $\left(\mathrm{m}^{*}\right)$ can be deduced from the following relation [28]:

$n^{2}=\varepsilon_{L}-\frac{e^{2}}{4 \pi^{2} c^{2} \varepsilon_{0}} \frac{N}{m^{*}} \lambda^{2}$

here $e$ the charge of the electron, and $\varepsilon_{0}$ the free space dielectric constant. From the linear plots of $n^{2}$ versus $\lambda^{2}$ that illustrated in Fig. 6c, the values of $\varepsilon_{L}$, and $\frac{N}{m^{*}}$ of $\mathrm{Se}_{90-x} \mathrm{Te}_{10} \mathrm{Ag}_{x}$ thin films are be estimated and listed in Table 1. It is clear that both the value of $\varepsilon_{L}$ and $\frac{N}{m^{*}}$ decrease with increasing the $\mathrm{Ag}$ content in $\mathrm{Se}_{90-x} \mathrm{Te}_{10} \mathrm{Ag}_{x}$ samples. It is worth noting that the $\varepsilon_{L}$ values are higher than $\varepsilon_{0}$ values. The rise in free charge carrier's contribution, during the polarizability process in these materials, is responsible for this tendency [20]. All the dispesion paramters such as $\lambda_{o}, n_{o}, S_{o}, \varepsilon_{L}$, and $\frac{N}{m^{*}}$ are decreased with increasing the Ag content. The evaluated value of $\lambda_{o}$ is agreed with the estimated value of $\lambda$ from the $n-\lambda$ curves which corresponds to the maximum value of $n$ (or $n_{\max }$ ).

The complex optical constants such as the complex dielectric function $\left(\tilde{\varepsilon}=\varepsilon_{r}+i \varepsilon_{i}\right)$ identify the optical characteristics of solid substances. The real portion of the dielectric constant $\left(\varepsilon_{r}\right)$ represents the optical resistivity of the media to the speed of light, whereas the imaginary portion $\left(\varepsilon_{i}\right)$ represents the influence of the dipole motion on the absorption energy through the material. In other words, $\varepsilon_{r}$ refers to the dispersion, while $\varepsilon_{i}$ refers to the electromagnetic wave propagating across the medium [29]. The loss factor, which equals the ratio between $\varepsilon_{r}$ and $\varepsilon_{i}$, may then be calculated. The following relationships can be used to describe the (a)
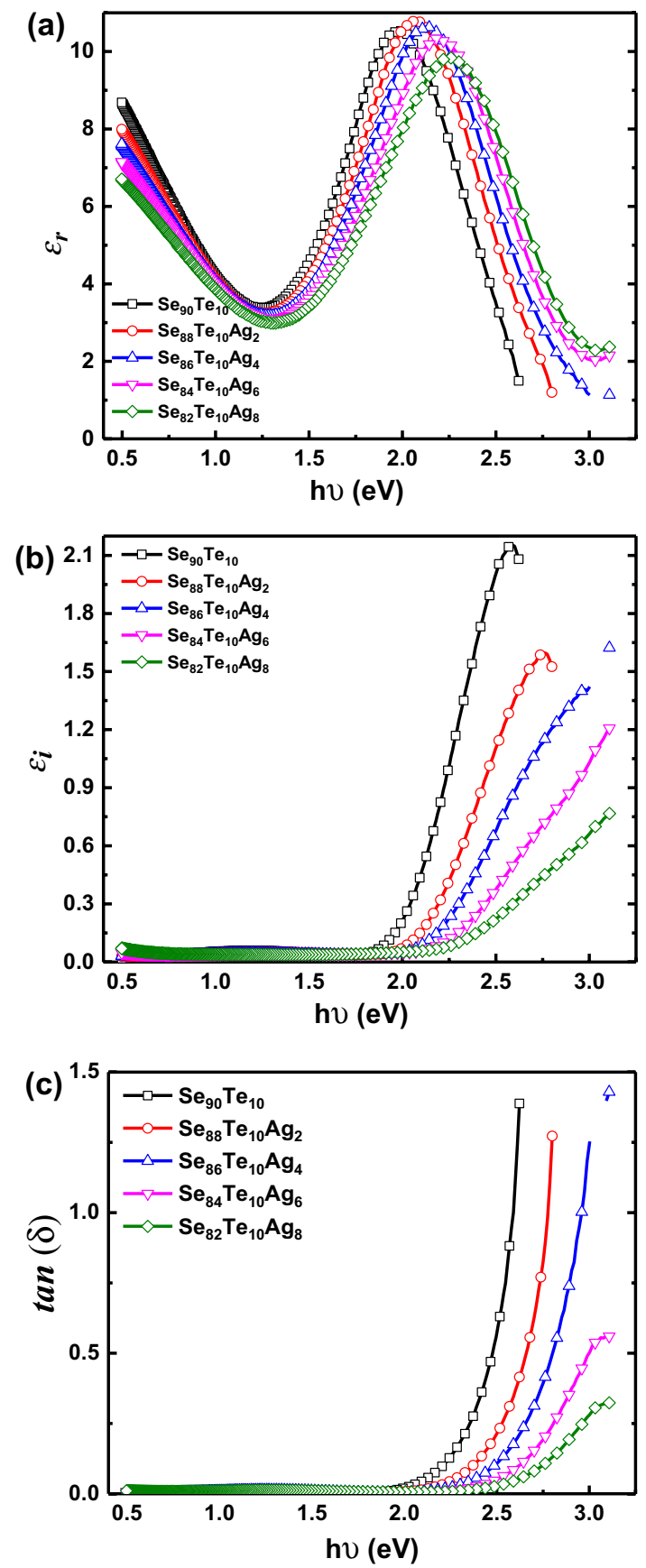

Fig. 7 Plots of a real dielectric constant $\left(\varepsilon_{\mathrm{r}}\right)$, b imaginary dielectric constant $\left(\varepsilon_{\mathrm{i}}\right)$, and $\mathbf{c} \tan (\delta)$ as a function of $(h \nu)$ for the as-prepared $\mathrm{Se}_{90-x} \mathrm{Te}_{10} \mathrm{Ag}_{x}$ films

components of the complex dielectric constant in terms of $n$ and $k_{\text {ex. }}[30,31]$ :

$$
\varepsilon_{r}=n^{2}-k_{e x .}^{2} \text { and } \varepsilon_{i}=2 n k_{e x} \text {. }
$$

Figure $7 \mathrm{a}$ and $\mathrm{b}$ show the change of $\varepsilon_{r}$ and $\varepsilon_{i}$ with $\lambda$ for the studied $\mathrm{Se}_{90-x} \mathrm{Te}_{10} \mathrm{Ag}_{x}$ films, respectively. It is observed that $\varepsilon_{r}$ is greater than $\varepsilon_{i}$ for the studied systems for all performed $h v$ at a higher wavelength. The value of $\varepsilon_{r}$ as well as $\varepsilon_{i}$ decrease with increasing $\mathrm{Ag}$ content while increasing 
with $\lambda$ for all investigated $\mathrm{Se}_{90-x} \mathrm{Te}_{10} \mathrm{Ag}_{x}$ films. As previously stated, the loss factor $(\tan (\delta))$, or the ratio of $\varepsilon_{i}$ to $\varepsilon_{r}$, maybe calculated using the following equation:

$\tan (\delta)=\frac{\varepsilon_{i}}{\varepsilon_{r}}$

Figure $7 \mathrm{c}$ displays the relationship between $\tan (\delta)$ and $(\mathrm{h} v)$ for investigated $\mathrm{Se}_{90-x} \mathrm{Te}_{10} \mathrm{Ag}_{x}$ thin films. Up to $h v$ $=2 \mathrm{eV}$, the value of $\tan (\delta)$ is relatively constant, but it rises for larger $\mathrm{h} \nu$ and decreases with increasing Ag concentration.

Electric susceptibility $\left(\chi_{c}\right)$ express the degree of polarization of dielectric medium when it is exposed to an applied electric field. In addition, the higher the value of $\chi_{c}$, the greater the solid's capacity to be polarized in reaction to an electric field. Now, using optical constants such as $n$ and $k_{e x}$, one may calculate the curve of $\chi_{c}$ as following [32]:

$\chi_{c}=\frac{1}{4 \pi}\left(n^{2}-k_{e x .}^{2}-\varepsilon_{0}\right)=\frac{1}{4 \pi}\left(\varepsilon_{r}-n_{o}^{2}\right)$

Figure 8 shows the curves of $\chi_{c}$ against $\lambda$ for $\mathrm{Se}_{90-x} \mathrm{Te}_{10} \mathrm{Ag}_{x}$ thin films. With increasing Ag content in the film, the evaluated values of $\chi_{c}$ for $\mathrm{Se}_{90-x} \mathrm{Te}_{10} \mathrm{Ag}_{x}$ thin films tend to decrease. The plots of $\chi_{c}$ reveal that it behaves similarly to $\varepsilon_{r}$, leading us to believe that the $\mathrm{Se}_{90-x} \mathrm{Te}_{10} \mathrm{Ag}_{x}$ thin films can be polarized in electric fields.

The inter-band transition strength $\left(J_{c v}(E)\right)$ could well be calculated using the major dipole selection principles of the solid's transitions [33]. The value of $J_{c v}(E)$ is precisely proportional to the probability of an electron transition from the full valence band to the empty conduction band and is connected to by the following equations [34]:

$J_{c v}(E)=\operatorname{Re}\left(J_{c v}(E)\right)+\operatorname{Im}\left(J_{c v}(E)\right)=\frac{4 \pi m_{*}^{2}}{e^{2} h^{2}} \frac{(h v)^{2}}{2}\left(\varepsilon_{r}+i \varepsilon_{i}\right)$

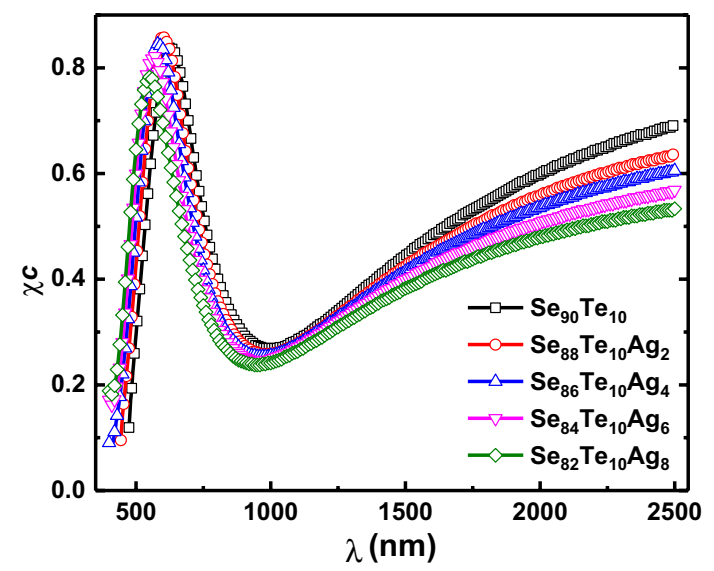

Fig. 8 Dependence of the electrical susceptibility $\left(\chi_{c}\right)$ on photon energy ( $h \nu$ ) for the as-prepared $\mathrm{Se}_{90-x} \mathrm{Te}_{10} \mathrm{Ag}_{x}$ films
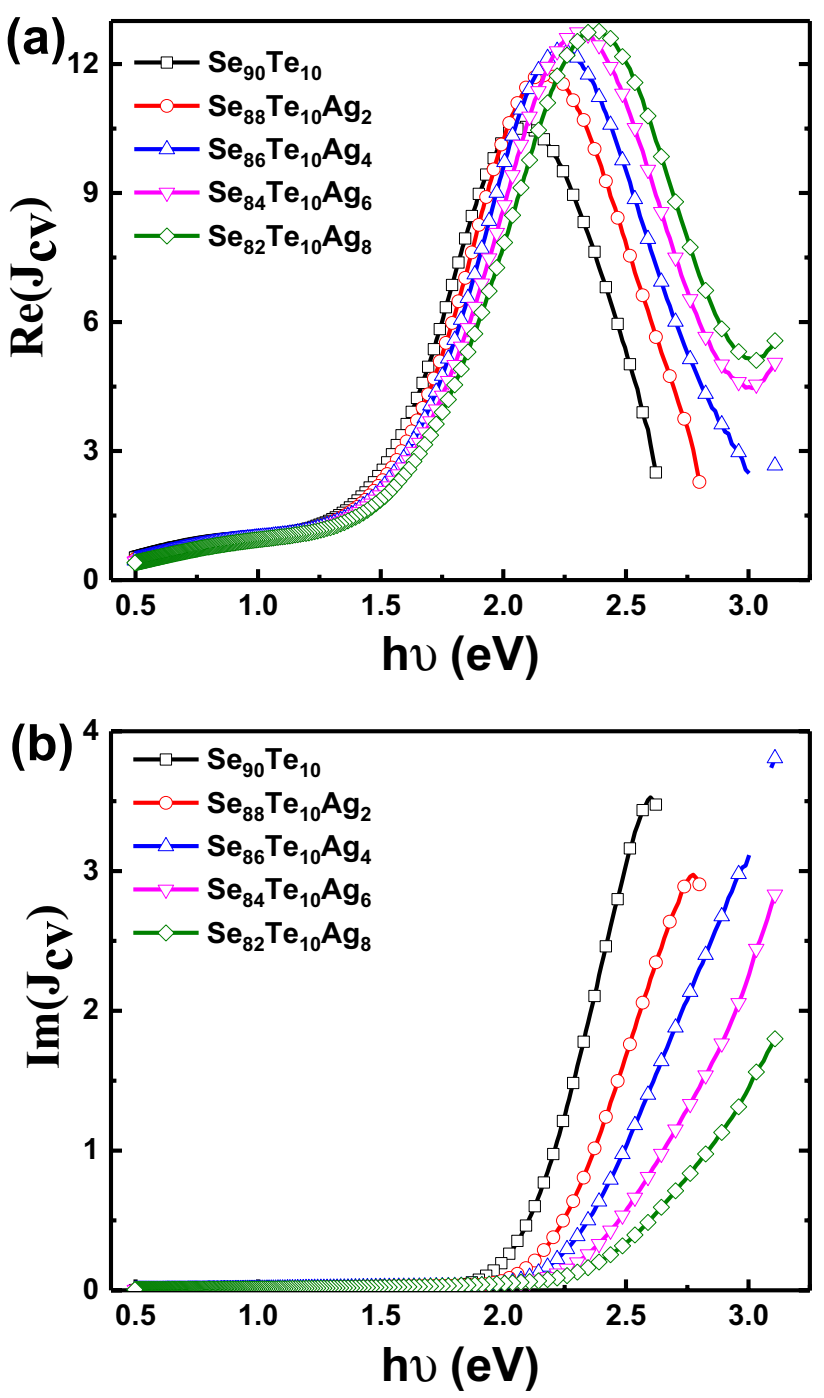

Fig. 9 Plots a the real $\left(\operatorname{Re}\left(\mathrm{J}_{\mathrm{cv}}\right)\right)$ and $\mathbf{b}$ imaginary $\left(\operatorname{Im}\left(\mathrm{J}_{\mathrm{cv}}\right)\right)$ parts of inter-band transition strength as a function of photon energy $(\mathrm{h} \nu)$ for the as-prepared $\mathrm{Se}_{90-x} \mathrm{Te}_{10} \mathrm{Ag}_{x}$ films

where $\operatorname{Re}\left(J_{c v}(E)\right)$ the real portion of the inter-band transition strength, and $\operatorname{Im}\left(J_{c v}(E)\right)$ the imaginary portion of the inter-band transition strength. To ease mathematical calculations, the prefix $\left(\frac{4 \pi m_{*}^{2}}{e^{2} h^{2}}\right)$ with the value $8.289 \times 10^{-6} \mathrm{~g} \cdot e \mathrm{~V}^{-2}$ might be used. Both of $J_{c v}(E)$ portions in terms of hv for $\mathrm{Se}_{90-x} \mathrm{Te}_{10} \mathrm{Ag}_{x}$ thin films are computed and presented in Fig. 9. It is shown that $J_{c v}(E)$ increases noticeably as photon energy exceeds $1.5 \mathrm{eV}$, revealing that the majority of light was absorbed for photon energy > $1.5 \mathrm{eV}$. This increases in the electron excitation, causing them to move to the conduction band from the valence band. The estimated value of $J_{c v}(E)$ grows substantially with rising $h \nu(>1.5 \mathrm{eV})$ as observed. Such behavior is consistent with the determined $E_{g}^{\text {ind }}$, which is about $1.5 \mathrm{eV}$ for the majority of the 
samples examined. Furthermore, the effect of $\mathrm{Ag}$ content in $\mathrm{Se}_{90-x} \mathrm{Te}_{10} \mathrm{Ag}_{x}$ thin films on $J_{c v}(E)$ behavior is quite comparable to the variation in $\sigma_{\text {opt. }}$ and $O D$.

The value of $E_{g}^{\text {ind }}$ and $n$ are basic physical factors that could be used to govern many electrical and optical parameters of chalcogenide films. In this context, Tripathy [35], Moss [34], Ravindra [36], Herve-Vandamme (HV) [37, 38] proposed various empirical equations that correlate between $n$ and $E_{g}^{\text {ind }}$, respectively, and the empirical equation for each suggestion is presented below:

$n_{T}=1.73 \times\left[1+1.9017 \times e^{-0.539 \times E_{g}^{\text {ind }}}\right]$

$n_{M}=\sqrt[4]{\frac{95}{E_{g}^{\text {ind }}}}$

$n_{R}=4.084-\left[0.62 \times E_{g}^{\text {ind }}\right]$

$n_{[H V]}=\sqrt{1+\left(\frac{13.6}{E_{g}^{\text {ind }}+3.47}\right)^{2}}$

The $n$ values determined using these formulas are based on $E_{g}^{\text {ind }}$ values. The dependence of $n$ on $E_{g}^{\text {ind }}$ for $\mathrm{Se}_{90-x} \mathrm{Te}_{10} \mathrm{Ag}_{x}$ thin films is listed in Table 2. Based on the predicted values of $n$ as a function of $E_{g}^{\text {ind }}$ in Table 2, it is worth mentioning here that $n$ is mostly determined by the value of $E_{g}^{\text {ind }}$, which is also determined by the Ag concentration in the $\mathrm{Se}_{90-x} \mathrm{Te}_{10} \mathrm{Ag}_{x}$ thin films. In general observation, greater optical bandgap materials have a smaller $n$. The estimated value of $n$ using various approaches and the average calculated value of $n$ is decreased with increasing the $\mathrm{Ag}$ content in the $\mathrm{Se}_{90-x} \mathrm{Te}_{10} \mathrm{Ag}_{x}$ compositions.

When a high-intensity light travels through a substance, nonlinear effects of $n$ may occur. The Kerr effects are the simplest of these, describing the link between variations in the refractive index $(\Delta n)$ and optical intensity $(I)$ using the equation $\Delta n=n_{2} I$. The nonlinear refractive index $\left(n_{2}\right)$ is a proportional constant that is strongly influenced by the intensity of incoming light. When a material is subjected to a strong electric field of incoming light, the change in polarizability must be proportionately prolonged to the square of the applied electric field [39]. Tichy and Ticha's relation [40] yields the value of $n_{2}$, which is a mix of Miller's popularised equation and $n_{o}$ from the WDD model, as shown below [41]:

$n_{2}=\frac{12 \pi \chi^{(3)}}{n_{o}}$

where $\chi^{(3)}$ is the third-order of non-linear susceptibility. The following equation can be used to calculate the value of $\chi^{(3)}$ [42]:
$\chi^{(3)}=B\left[\chi^{(1)}\right]^{4}$

here $\chi^{(1)}$ denotes linear susceptibility and can be determined using the folwing equation:

$\chi^{(1)}=\frac{E_{d}}{4 \pi E_{o}}$

$\mathrm{B}$ is constant and equals $1.7 \times 10^{-10}$ (for $\chi^{(3)}$ in the electrostatic system of units), and $\chi^{(3)}$ is written as follows:

$\chi^{(3)}=\frac{B}{16 \pi^{4}}\left(n_{0}^{2}-1\right)^{4}$

The estimated values of $n_{2}$ for $\mathrm{Se}_{90-x} \mathrm{Te}_{10} \mathrm{Ag}_{x}$ thin films are summarized in Table 3. It clears the estimated values of $n_{2}, \chi^{(1)}$, and $\chi^{(3)}$ decreases with the increase in the $\mathrm{Ag}$ content of the studied $\mathrm{Se}_{90-x} \mathrm{Te}_{10} \mathrm{Ag}_{x}$ thin films.

The optical surface resistance $\left(R_{s}\right)$ and thermal emissivity $\left(\varepsilon_{t h}\right)$ are connected to the photon energy or wavelength. The photonic irritation of electrons on the surface of thin film gives rise to the parameter $\varepsilon_{t h}$. The following formula expresses $R_{s}$ of thin films based on the relationship of absorption coefficient [43], and $\sigma_{\text {opt. }}$ [42]:

$R_{s}=-\frac{4 \pi}{c} \times \frac{1}{n \times \ln (T)}$

According to Fig. 10a ( $R_{s}$ versus $\left.\lambda\right), R_{s}$ increases as the value of $\lambda$ increases for the studied thin films. Finally, as a result of Kirchhoff's equation, one may express $\varepsilon_{t h}$ [44]:

$\varepsilon_{\text {th }}=1-\left[1+\left(2 \varepsilon_{0} c \times R_{S}\right)\right]^{-2}$

Figure 10b illustrates the connection between $\varepsilon_{t h}$ and $\lambda$ for $\mathrm{Se}_{90-x} \mathrm{Te}_{10} \mathrm{Ag}_{x}$ films. The spectrum of $\varepsilon_{t h}$ for $\mathrm{Se}_{90-x} \mathrm{Te}_{10} \mathrm{Ag}_{x}$ films is variable and it could vary with other parameters such as $\lambda$, the material's temperature, the measurement direction, and the surface conditions. Variations in $\varepsilon_{t h}$ can have a significant impact on the direction of observation. Furthermore, the effect of $\mathrm{Ag}$ ratio in $\mathrm{Se}_{90-x} \mathrm{Te}_{10} \mathrm{Ag}_{x}$ thin films on the behaviors of $R_{s}$ and $\varepsilon_{t h}$ is quite comparable to the change in $\sigma_{\text {opt. }}, J_{c v}(E)$, and $O D$.

The energy could be absorbed in a material as a result of the single-electron transitions and/or collective processes produced inside the solid. Such processes are described by the volume energy loss function (VELF) and the surface energy loss function (SELF) functions. These functions quantify the chance that fast electrons pass inside a bulk material or on its surface and cause a loss in the incident energy. By using the evaluated $\varepsilon_{r}$ and $\varepsilon_{i}$ the VELF and SELF values can be calculated from the following equations [44]: 
Table 2 Refractive index obtained from the deduced value of $E_{g}$ by various approaches along with its average value for the as-prepared $\mathrm{Se}_{90-x} \mathrm{Te}_{10} \mathrm{Ag}_{x}$ thin film

\begin{tabular}{llllll}
\hline$n$ & $x=0$ & $x=2$ & $x=4$ & $x=6$ & $x=8$ \\
\hline$n_{T}$ & 3.08 & 3.02 & 2.98 & 2.94 & 2.92 \\
$n_{M}$ & 2.75 & 2.72 & 2.70 & 2.68 & 2.66 \\
$n_{R}$ & 3.06 & 3.01 & 2.97 & 2.94 & 2.91 \\
$n_{[H V]}$ & 2.58 & 2.46 & 2.41 & 2.34 & 2.30 \\
Average $n$ & 2.87 & 2.80 & 2.77 & 2.73 & 2.70 \\
\hline
\end{tabular}

$V E L F=\frac{\varepsilon_{i}^{2}}{\varepsilon_{i}^{2}+\varepsilon_{r}^{2}}$

$S E L F=\frac{\varepsilon_{i}^{2}}{\varepsilon_{i}^{2}+\left(\varepsilon_{r}+1\right)^{2}}$

Figure $11 \mathrm{a}$ and $\mathrm{b}$ illustrate the dependency of both the SELF and VELF as a function of $h \nu$, respectively, for the studied $\mathrm{Se}_{90-x} \mathrm{Te}_{10} \mathrm{Ag}_{x}$ films. It is clear that with two parameters VELF and SELF at $h \nu \geq 2 \mathrm{eV}$, increase with increasing while the deduced values of VELF and SELF reduce with increasing Ag ratio.

The calculated $\varepsilon_{\infty}$ aids in determining some electronic characteristics of $\mathrm{Se}_{90-x} \mathrm{Te}_{10} \mathrm{Ag}_{x}$ films including the valence electron plasmon energy, the average energy gap or Penn gap $\left(E_{p}\right)$, Fermi energy $\left(E_{F}\right)$, and electronic polarizability $\left(\alpha_{p}\right)$. The value of the valence electron plasmon energy $\left(\hbar \omega_{\mathrm{p}}\right)$ is determined by [45]

$\hbar \omega_{p}=28.8 \times \sqrt{\frac{n_{e f f} \rho}{M}}$

where $\rho$ is the glass density, $n_{\text {eff }}$ the total number of valence electrons, and $M$ the molecular weight for the investigated films. The following formula can be used to calculate the value of $\omega_{p}$ :

Table 3 Linear optical susceptibility $\left(\chi^{(1)}\right)$, third order of non-linear susceptibility $\left(\chi^{(3)}\right)$, non-linear refractive index $\left(n_{2}\right)$ and the linear refractive index $\left(n_{o}\right)$ for as-prepared $\mathrm{Se}_{90-x} \mathrm{Te}_{10} \mathrm{Ag}_{x}$ thin film

\begin{tabular}{lllcc}
\hline $\begin{array}{l}\text { Ag content } \\
\text { (at.\%) }\end{array}$ & $n_{\boldsymbol{o}}$ & $\chi^{(1)}[\mathrm{esu}]$ & $\begin{array}{l}\chi^{(3)} \times \mathbf{1 0}^{-12} \\
{[\mathrm{esu}]}\end{array}$ & $\begin{array}{l}n_{2} \times 10^{-10} \\
{[\mathrm{esu}]}\end{array}$ \\
\hline 0 & 2.70 & 2.00 & 170.46 & 23.81 \\
2 & 2.19 & 1.20 & 22.61 & 3.89 \\
4 & 2.01 & 0.96 & 9.30 & 1.74 \\
6 & 1.89 & 0.82 & 4.76 & 0.95 \\
8 & 1.80 & 0.72 & 2.74 & 0.57 \\
\hline
\end{tabular}
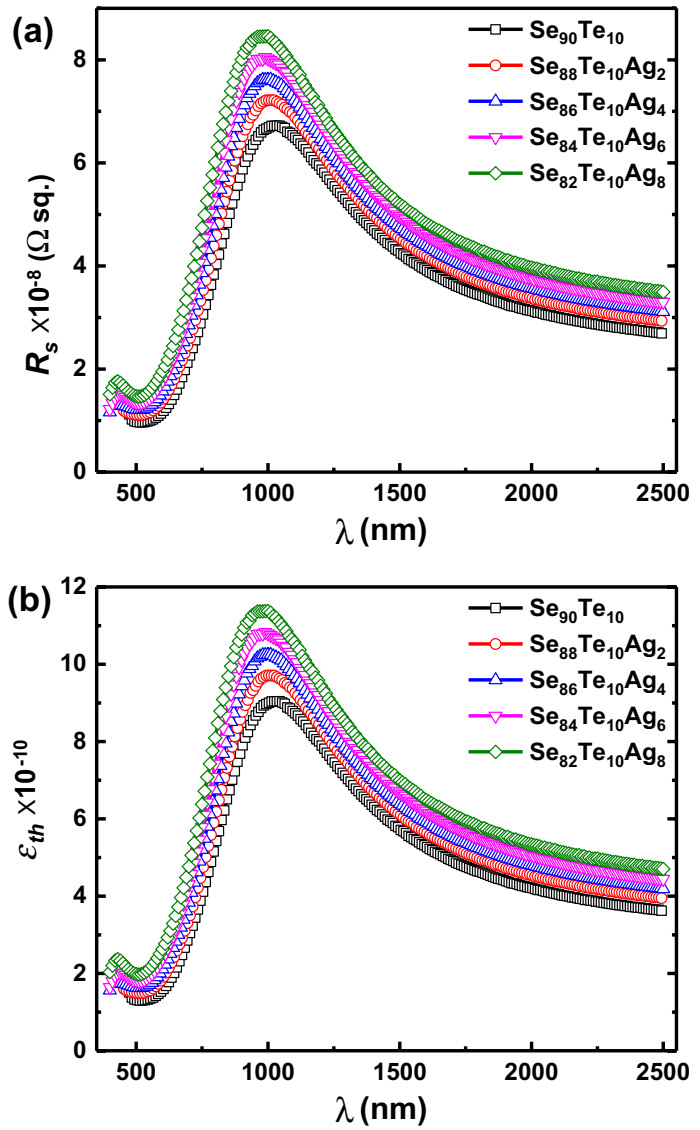

Fig. 10 Dependence of a the optical sheet resistance $\left(\mathrm{R}_{\mathrm{s}}\right)$, b the thermal emissivity $\left(\varepsilon_{\mathrm{th}}\right)$ on photon energy $(\mathrm{h} \nu)$ for the as-prepared $\mathrm{Se}_{90-x} \mathrm{Te}_{10} \mathrm{Ag}_{x}$ films

$\omega_{p}=\sqrt{\frac{e^{2}}{\varepsilon_{0} \varepsilon_{L}} \frac{N}{m^{*}}}$

The Penn model [45] was used to calculate $\mathrm{E}_{\mathrm{p}}$ for $\mathrm{Se}_{90-x} \mathrm{Te}_{10} \mathrm{Ag}_{x}$ thin film as follows:

$E_{p}=\frac{\hbar \omega_{p}}{\sqrt{\varepsilon_{\infty}-1}}$

From the determined $\varepsilon_{\infty}$ and $\hbar \omega_{p}$, the values of $E_{\mathrm{p}}$ are presented at different $\mathrm{Ag}$ compositions in the $\mathrm{Se}-\mathrm{Te}-\mathrm{Ag}$ alloy in Table 4. Phillips [19] had proposed that the imaginary component of the dielectric constant is an empirically observable variable that depends on a comparable average. The value of $E_{\mathrm{F}}$ is calculated using $\hbar \omega_{p}$ from the following equation:

$E_{F}=0.2948 \times \sqrt[3]{\left(\hbar \omega_{p}\right)^{4}}$ 
The estimated value of $E_{F}$ for the $\mathrm{Se}_{90-x} \mathrm{Te}_{10} \mathrm{Ag}_{x}$ thin film is estimated and listed in Table 4.

A nonlinear optical system is concerned with the nonlinear component of polarization, which is the primary source of wave production when electronic polarization takes place inside the glasses. The electron gas cloud is pushed from the nucleus due to internal charge distribution, generating a net dipole moment. The mechanical restoring forces become nonlinear due to the net displacement. Continuous efforts have been made to enhance the computations of polarizabilities in solids [46, 47]. The prediction of a valid value for $\alpha_{p}$
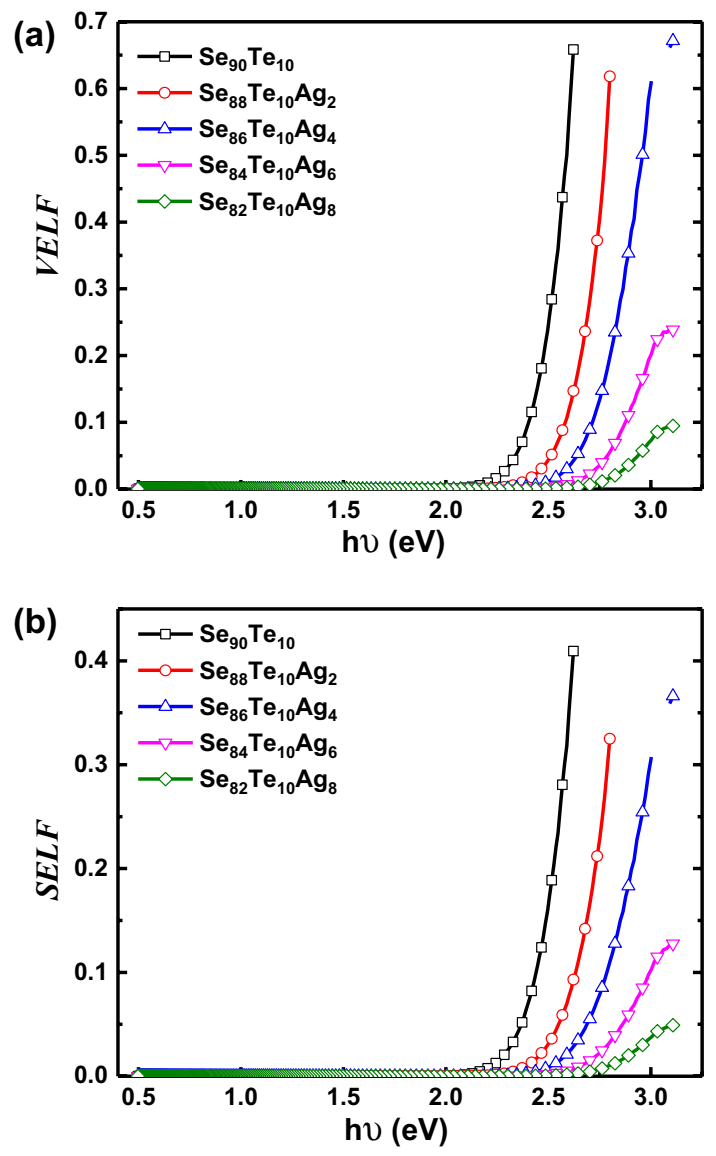

Fig. 11 Variation of a surface energy loss function (SELF) and $\mathbf{b}$ volume energy loss function (VELF) as a function of the photon energy $(\mathrm{h} \nu)$ for the as-prepared $\mathrm{Se}_{90-x} \mathrm{Te}_{10} \mathrm{Ag}_{x}$ films using theoretical approaches has made major contributions and brought new vigor to intensely active sectors as they seek novel nonlinear optical materials.

The value of $\alpha_{p}$ for a material may be determined using the classical theory of dielectric constant [31]:

$\alpha_{p}=3.9 \times 10^{-25} \frac{M}{\rho}\left[\frac{\left(\hbar \omega_{p}\right)^{2} s_{o}}{\left(\hbar \omega_{p}\right)^{2} s_{o}+3 E_{p}^{2}}\right]$

here $S_{\mathrm{o}}$ is a characteristic constant for the material and is provided by [45]:

$s_{o}=1-\frac{E_{p}}{4 E_{F}}+\frac{1}{3}\left(\frac{E_{p}}{4 E_{F}}\right)^{2}$

The numerical values of $\alpha_{p}$ and $s_{o}$ are summarized in Table 4 at various Ag content in the studied thin films. It is observed that $\alpha_{p}, \Psi\left(=\hbar \omega_{p}\right)$, and $s_{o}$ are slightly decreases with the rising $\mathrm{Ag}$ content in the studied compositions.

Because of their higher absorption coefficient, $\mathrm{Se}-\mathrm{Te}-\mathrm{Ag}$ films can be used in optical data storage in general [48, 49]. In addition, the investigated optical properties of $\mathrm{Se}_{90-x} \mathrm{Te}_{10} \mathrm{Ag}_{x}$ films is a prospective system for optical elements, gratings, photo-doping, optical memory, waveguides, holography, biochemical sensors, rewritable discs, solid electrolytes, batteries, and other uses exist in optics, optoelectronics, chemistry, and biology.

\section{Conclusions}

Thermal evaporation was used to deposit $100 \mathrm{~nm}$ thick amorphous $\mathrm{Se}_{90-x} \mathrm{Te}_{10} \mathrm{Ag}_{x}(x=0,2,4,6$, and 8 at.\%) thin films from bulk materials onto a glass substrate. The transmittance and reflectance spectra, at $\lambda$ equal to $250-2500 \mathrm{~nm}$, were used to assess various linear and nonlinear optical and electrical characteristics of $\mathrm{Se}_{90-x} \mathrm{Te}_{10} \mathrm{Ag}_{x}$ thin films. The linear optical parameters were utilized to calculate the nonlinear optical parameters, and the refractive index was calculated using several approaches based on the optical bandgap. Except for the optical band gap, the substitution of Se atoms by $\mathrm{Ag}$ reduces all of the investigated optical and electronic
Table 4 Electronic parameters such as the Penn gap $\left(E_{p}\right)$, Fermi energy $\left(E_{F}\right)$, the plasma resonance frequency $\left(\omega_{\mathrm{p}}\right)$, the valence electron plasmon energy $\left(\Psi=\omega_{\mathrm{p}}\right)$, and the electronic polarizability $\left(\alpha_{p}\right)$ for as-prepared $\mathrm{Se}_{90-x} \mathrm{Te}_{10} \mathrm{Ag}_{x}$ thin film

\begin{tabular}{lllllll}
\hline $\begin{array}{l}\text { Ag content } \\
\text { (at.\%) }\end{array}$ & $\mathrm{E}_{\mathbf{p}}(\mathrm{eV})$ & $\mathrm{E}_{\mathbf{F}}(\mathrm{eV})$ & $\omega_{\mathbf{p}} \times 10^{15}(\mathrm{~Hz})$ & $\Psi(\mathrm{eV})$ & $s_{o}$ & $\alpha_{\mathbf{p}} \times 10^{-24}\left(\mathrm{~cm}^{3}\right)$ \\
\hline 0 & 2.04 & 4.92 & 2.00 & 8.27 & 0.90 & 6.09 \\
2 & 2.11 & 5.03 & 2.03 & 8.41 & 0.90 & 6.05 \\
4 & 2.20 & 5.04 & 2.04 & 8.42 & 0.89 & 5.98 \\
6 & 2.32 & 4.97 & 2.02 & 8.34 & 0.89 & 5.88 \\
8 & 2.45 & 4.90 & 2.00 & 8.25 & 0.88 & 5.78 \\
\hline
\end{tabular}


parameters such as absorption coefficient, extinction coefficient, optical conductivity, optical susceptibility, sheet resistance, and thermal emissivity. The following parameters show opposite trends around the incident photon energy that equals the optical bandgap: transmittance, reflectance, linear refractive index, real dielectric constant, electrical susceptibility, a real part of inter-band transition strength, optical sheet resistance, and thermal emissivity. Similarly, the following parameters: absorption coefficient, optical density, extinction coefficient, imaginary dielectric constant, optical conductivity, electrical conductivity, the imaginary part of inter-band transition strength, SELF, and VELF show different types of change (slowly, and significantly) around the incident photon energy that equal to the optical bandgap. The change in the optical and electronic parameters with the substitution of Se with Ag may be due to the change in the amount of disorder, the density of defect states, and polarizability in the systems. The differences might also be explained in terms of the cohesive energy and electronegativity differences between the elements used to create the $\mathrm{Se}_{90-x} \mathrm{Te}_{10} \mathrm{Ag}_{x}$ glasses. These materials may be useful for optical memory systems due to their high absorption coefficients and compositional dependency on absorption.

Author Contributions All authors are equally contributed to this article.

Funding Open access funding provided by The Science, Technology. This research received no external funding.

Data Availability All data generated or analyzed during this study are included in this article.

\section{Declarations}

Conflict of interest The authors declare that they have no known competing financial interests or personal relationships that could have appeared to influence the work reported in this article.

Open Access This article is licensed under a Creative Commons Attribution 4.0 International License, which permits use, sharing, adaptation, distribution and reproduction in any medium or format, as long as you give appropriate credit to the original author(s) and the source, provide a link to the Creative Commons licence, and indicate if changes were made. The images or other third party material in this article are included in the article's Creative Commons licence, unless indicated otherwise in a credit line to the material. If material is not included in the article's Creative Commons licence and your intended use is not permitted by statutory regulation or exceeds the permitted use, you will need to obtain permission directly from the copyright holder. To view a copy of this licence, visit http://creativecommons.org/licenses/by/4.0/.

\section{References}

1. J.-L. Adam, X. Zhang (eds.), Chalcogenide glasses: preparation, properties and applications (Woodhead, Swaston, 2014)
2. A. Lotnyk, M. Behrens, B. Rauschenbach, Phase change thin films for non-volatile memory applications. Nanoscale Adv. 1(10), 3836-3857 (2019)

3. Y. Liu, C. Chen, Y. Zhou, R. Kondrotas, J. Tang, Butyldithiocarbamate acid solution processing: its fundamentals and applications in chalcogenide thin film solar cells. J. Mater. Chem. C 7(36), 11068-11084 (2019)

4. N. Nedelcu, Applications of the chalcogenide ternary thin films. A review. Rom. J. Mech. 4(2), 47-64 (2020)

5. S. Saha, M. Johnson, F. Altayaran, Y. Wang, D. Wang, Q. Zhang, Electrodeposition fabrication of chalcogenide thin films for photovoltaic applications. Electrochem 1(3), 286-321 (2020)

6. A. Elkorashy, H. Elzahed, M. Radwan, A.M. Abdalla, Influence of composition and heat treatment on the structure of Se-Te films. Thin Solid Films 261, 328-333 (1995)

7. G. Zhao, Y.E. Zhao, Y.B. Wang, C.J. Ji, Ab initio molecular dynamics study of liquid $\mathrm{Se}_{30} \mathrm{Te}_{70}$ : structural, electronic and dynamical properties. Phys. Scr. 82, 1 (2010)

8. M.F. Kotkata, M.K. El-Mously, A survey of amorphous Se-Te semiconductors and their characteristic aspects of crystallization. Acta Phys. Hung. 54(3), 303-312 (1983)

9. A.E. Bekheet, N.A. Hegab, M.A. Afifi, H.E. Atyia, E.R. Sharaf, The effect of $\mathrm{Ag}$ addition on the optical properties of $\mathrm{Se}_{90} \mathrm{Te}_{10}$ films. Appl. Surf. Sci. 255, 4590-4594 (2009)

10. M.A. Abdel-Rahim, M.A.S. Hammam, A.A. Abu-Sehly, M.M. Hafiz, Composition effect on the pre-crystallization and crystallization characteristics for $\mathrm{Se}_{90-\mathrm{x}} \mathrm{Te}_{10} \mathrm{Ag}_{\mathrm{x}}$. J. Alloys Compd. 728, 1346-1361 (2017)

11. A. Gupta, K. Malik, R. Kumar, Effect of vacuum thermal annealing on optical properties of amorphous $\left(\mathrm{Se}_{80} \mathrm{Te}_{20}\right)_{94} \mathrm{Ag}_{6}$ chalcogenide thin films prepared by thermal evaporation technique. J. Phys.: Conf. Ser. 1644(1), 12035-12039 (2020)

12. M. Mishra, R. Chauhan, K.K. Srivastava, The effect of annealing on some optical properties in $\mathrm{Se}-\mathrm{Te}-\mathrm{Ag}$ glasses. Integr. Ferroelectr. 118(1), 34-44 (2010)

13. M.A.S. Hammam, M.A. Abdel-Rahim, M.M. Hafiz, A.A. AbuSehly, New combination of non-isothermal kinetics-revealing methods. J. Therm. Anal. Calorim. 128(3), 1391-1405 (2017)

14. D. Singh, S. Kumar, R. Thangaraj, Optical and electrical properties of as-prepared and annealed $\left(\mathrm{Se}_{80} \mathrm{Te}_{20}\right)_{100-\mathrm{x}} \mathrm{Ag}_{\mathrm{x}}(0 \leq \mathrm{x} \leq 4)$ ultra-thin films. J. Non-Cryst. Solids 358(20), 2826-2834 (2012)

15. S. Singh, S. Kumar, Investigation of optical constants and optical band gap for amorphous $\mathrm{Se}_{40-\mathrm{x}} \mathrm{Te}_{60} \mathrm{Ag}_{\mathrm{x}}$ thin films. Chalcogenide Lett. 14(4), 139-146 (2017)

16. R.M. Hassan, S. Moustafa, A.M. Abd-Elnaiem, Optimization of the linear and nonlinear optical properties of amorphous $\mathrm{As}_{30} \mathrm{Te}_{69} \mathrm{Ga}_{1}$ thin films by the annealing process. J. Mater. Sci. Mater. Electron. 31(22), 20043-20059 (2020)

17. G. Abbady, A. Qasem, A.M. Abd-Elnaiem, Optical parameters and electronic properties for the transition of the amorphouscrystalline phase in $\mathrm{Ge}_{20} \mathrm{Te}_{80}$ thin films. J. Alloys Compd. 842, 155705 (2020)

18. J.I. Pankove, Optical Processes in Semiconductors (Courier Dover Publications, New York, 2012)

19. J. Tauc, Amorphous and Liquid Semiconductors (Plenum Publishing Corporation, New York, 1974)

20. F. Urbach, The long-wavelength edge of photographic sensitivity and of the electronic absorption of solids. Phys. Rev. 92(5), 1324 (1953)

21. M. Marc Kastner, H. Fritzche, Defect chemistry of lone-pair semiconductors. Philos. Mag. B 37(2), 199-215 (1978)

22. T. Petkova, M. Mitkova, Optical band-gap and activation energy of thin films from the Se-Ag-I and Te-Ag-I systems. Radiat. Eff. Defects Solids 137(1-4), 183-186 (1995) 
23. P. Sharma, S.C. Katyal, Far-infrared transmission and bonding arrangement in $\mathrm{Ge}_{10} \mathrm{Se}_{90-\mathrm{x}} \mathrm{Te}_{\mathrm{x}}$ semiconducting glassy alloys. J. Non-Cryst. Solids 354(32), 3836-3839 (2008)

24. O.S. Heavens, Optical properties of thin films. Rep. Prog. Phys. 23(1), 1-65 (1960)

25. P. Sharma, V. Sharma, S.C. Katyal, Variation of optical constants in $\mathrm{Ge}_{10} \mathrm{Se}_{60} \mathrm{Te}_{30}$ thin film. Chalcogenide Lett 3(10), 73-79 (2006)

26. S.H. Wemple, Refractive-index behavior of amorphous semiconductors and glasses. Phys. Rev. B 7, 3767-3777 (1973)

27. A.K. Walton, T.S. Moss, Determination of refractive index and correction to effective electron mass in PbTe and PbSe. Proc. Phys. Soc. 81(3), 509-513 (1963)

28. J.N. Zemel, J.D. Jensen, R.B. Schoolar, Electrical and optical properties of epitaxial films of $\mathrm{PbS}, \mathrm{PbSe}, \mathrm{PbTe}$, and $\mathrm{SnTe}$. Phys. Rev. 140(1A), A330 (1965)

29. L. Tsang, J.A. Kong, K.-H. Ding, Scattering of electromagnetic waves: theories and applications, vol. 27 (Wiley, New York, 2004)

30. M.M. Hafiz, H.M. Kotb, M.A. Dabban, A.Y. Abdel-Latif, Optical properties of $\mathrm{Cd}_{20} \mathrm{Se}_{80-\mathrm{x}} \mathrm{M}_{\mathrm{x}}$ (M: Zn, In, and $\mathrm{Sn}$ ) thin film alloys. Opt. Laser Technol. 49, 188-195 (2013)

31. V. Kumar, B.S.R. Sastry, Heat of formation of ternary chalcopyrite semiconductors. J. Phys. Chem. Solids 66(1), 99-102 (2005)

32. F. Abelès (ed.), Optical properties of solids, vol. 138 (NorthHolland, Amsterdam, 1972)

33. R.H. French, H. Müllejans, D.J. Jones, Optical properties of aluminum oxide: determined from vacuum ultraviolet and electron energy-loss spectroscopies. J. Am. Ceram. Soc. 81(10), 25492557 (1998)

34. R.H. French, Origins and applications of London dispersion forces and Hamaker constants in ceramics. J. Am. Ceram. Soc. 83(9), 2117-2146 (2000)

35. S.K. Tripathy, Refractive indices of semiconductors from energy gaps. Opt. Mater. 46, 240-246 (2015)

36. N.M. Ravindra, S. Auluck, V.K. Srivastava, On the Penn gap in semiconductors. Phys. Status Solidi (b) 93(2), 155-160 (1979)

37. P. Herve, L.K.J. Vandamme, General relation between refractive index and energy gap in semiconductors. Infrared Phys. Technol. 35(4), 609-615 (1994)

38. P.J.L. Herve, L.K.J. Vandamme, Empirical temperature dependence of the refractive index of semiconductors. J. Appl. Phys. 77(10), 5476-5477 (1995)
39. P. Sharma, S.C. Katyal, Linear and nonlinear refractive index of As-Se-Ge and Bi doped As-Se-Ge thin films. J. Appl. Phys. 107(11), 113527 (2010)

40. H. Ticha, L. Tichy, Semiempirical relation between non-linear susceptibility (refractive index), linear refractive index and optical gap and its application to amorphous chalcogenides. J. Optoelectron. Adv. Mater 4(2), 381-386 (2002)

41. S.H. Wemple, M. Didomenico, Behavior of the electronic dielectric constant in covalent and ionic materials. Phys. Rev. B 3, 1338-1351 (1971)

42. C. Charles, Wang, Empirical relation between the linear and the third-order nonlinear optical susceptibilities. Phys. Rev. B 2(6), 2045 (1970)

43. A. Abu El-Fadl, M.M. Hafiz, M.M. Wakaad, A.S. Aashour, Influence of $\gamma$-radiation on the optical parameters of $\mathrm{Ag}_{10} \mathrm{Te}_{90}$ thin films. Radiat. Phys. Chem. 76(1), 61-66 (2007)

44. M. Reidinger, M. Rydzek, C. Scherdel, M. Arduini-Schuster, J. Manara, Low-emitting transparent coatings based on tin doped indiumoxide applied via a sol-gel routine. Thin Solid Films 517(10), 3096-3099 (2009)

45. D.R. Penn, Wave-number-dependent dielectric function of semiconductors. Phys. Rev. 128(5), 2093 (1962)

46. V.P. Gupta, V.K. Srivastava, P.N.L. Gupta, Electronic properties of chalcopyrites. J. Phys. Chem. Solids 42(12), 1079-1085 (1981)

47. R.R. Reddy, Y.N. Ahammed, K.R. Gopal, P.A. Azeem, T.V.R. Rao, P. Mallikarjuna Reddy, Optical electronegativity, bulk modulus and electronic polarizability of materials. Optical Mater. 14(4), $355-358$ (2000)

48. A. El-Denglawey et al., Optical and mechanical properties of Ag doped thermally evaporated SeTe thin films for optoelectronic applications. J. Phys. Chem. Solids 159, 110291 (2021)

49. M. Frumar, T. Wagner, Ag doped chalcogenide glasses and their applications. Curr. Opin. Solid State Mater. Sci. 7(2), 117-126 (2003)

Publisher's Note Springer Nature remains neutral with regard to jurisdictional claims in published maps and institutional affiliations. 